BMJ Open Sport \& Exercise Medicine

\title{
Perceptions of group exercise courses and instructors among Quebec adults
}

Monique Gilbert, Philippe Chaubet, Antony Karelis, Kelsey Needham Dancause

To cite: Gilbert M, Chaubet $P$, Karelis A, et al. Perceptions of group exercise courses and instructors among Quebec adults. BMJ Open Sport \& Exercise Medicine 2017;3:e000278. doi:10.1136/ bmjsem-2017-000278

- Additional material is published online only. To view please visit the journal online (http://dx.doi.org/10.1136/ bmjsem-2017-000278).

Accepted 16 0ctober 2017
ABSTRACT

Background Group exercise courses are popular among adults, but dropout rates are high. Studies of relationships between participants' perceptions and their participation might highlight factors to target to improve adherence and re-enrolment.

Methods We used a mixed-methods approach to analyse perceptions of group exercise courses and instructors among 463 adults. Participants completed the Exercise Barriers and Benefits Scale, questionnaires on perceptions of the instructor and course, and non-participation. We assessed participation from weeks 2-4 and 5-10, and re-enrolment. We analysed relationships between perceptions and re-enrolment using linear regression and mediation analyses. We conducted group interviews with 11 participants.

Results Predictors of re-enrolment included early participation $(\beta=0.11, P=0.029)$ and perceptions of the group social climate $(P=0.027)$. Perceptions of the group mediated the relationship between early participation and re-enrolment ( $95 \% \mathrm{Cl} 0.0036$ to 0.0471$)$ : early participation predicted more positive perceptions $(\beta=2.11$, $P=0.003)$, which predicted re-enrolment $(\beta=0.01$, $\mathrm{P}=0.006$ ). Qualitative analyses highlighted instructors' roles in promoting social exchange and integrating participants into the group.

Conclusions The social climate of group exercise courses is a key factor predicting re-enrolment. Early participation predicts re-enrolment on its own, and also promotes positive perceptions of the group. Instructors can target these factors by sensitising participants to the importance of early participation, and promoting social exchange.

\section{INTRODUCTION}

The level of physical activity among adults worldwide is largely insufficient, particularly in high-income countries. ${ }^{1}$ For example, only $18 \%-19 \%$ of Canadian adults ${ }^{2}$ and $10 \%$ of US adults ${ }^{4}$ meet the recommended $150 \mathrm{~min}$ of moderate-intensity physical activity per week. Given its role in chronic disease risk, ${ }^{5}$ promoting lifelong physical activity is a top public health priority. ${ }^{56}$

The number of people who rely on personal trainers and instructors of group exercise courses has increased in recent years. ${ }^{7}$ Group exercise courses are one of the most popular leisure-time exercise activities among adults: $43 \%$ of adult gym members in the $\mathrm{USA}^{8}$

\section{What are the new findings?}

- Given the number of people who participate in group exercise courses, promoting adherence is an important way to help adults to remain physically active. Our study shows that social connections within the group exercise course are a key factor predicting re-enrolment.

- Factors related to individual instructor characteristics were less important predictors of re-enrolment.

- Efforts to promote exercise adherence might be best focused on developing a positive social climate in the first few weeks of the course.

participate in group exercise. Thus, group exercise courses offer an important avenue for adults to incorporate physical activity into their lives.

Despite their popularity, approximately $50 \%$ of participants who begin an exercise programme drop out within 6 months. ${ }^{9}{ }^{10} \mathrm{We}$ know little about factors that influence participants' perceptions of leisure-time group exercise courses and that might predict adherence or re-enrolment. ${ }^{11}$ One study assessed relationships between individual, instructor and group characteristics and satisfaction among 29 adults, highlighting the importance of the group social climate, and perceptions of instructor behaviour and individual competence. ${ }^{11}$ This study provided an excellent perspective of key variables affecting satisfaction, but did not assess adherence. Other research has analysed participants' perspectives of personal trainers ${ }^{12}$ and their role in behavioural change in general, ${ }^{13}$ but not within the group context. Some researchers have tested relationships between group social and task cohesion and adherence to group exercise courses, ${ }^{14}$ and have tracked changes in group cohesion over time. ${ }^{15} 16$ However, individual and instructor characteristics were not assessed. Thus, further studies remain necessary.

Our objectives were to understand relationships between participants' perceptions of leisure-time group exercise courses, instructors and their participation. This might 
highlight factors that could be targeted to improve adherence. We used a mixed-methods approach, ${ }^{17}$ incorporating quantitative analyses to highlight statistical patterns and qualitative analyses to contextualise participants' lived reality.

\section{METHODS}

\section{Participants and setting}

Participants were adults enrolled in group exercise courses during the Winter 2016 (January-March) period at Cardio Plein Air (CPA), which offers outdoor exercise sessions throughout Quebec, and Conditionnement Physique Boucherville, which offers indoor exercise sessions in Boucherville, Quebec. Like many similar organisations in Quebec, these organisations have fixed beginning and end dates for each session, which usually last from 10 to 15 weeks. Thus, people who wish to participate in a session enrol at the beginning, and must re-enrol for subsequent sessions if they wish to continue.

The first group of participants was recruited from the CPA enrolment database. Participants received an informational email, with the consent form. The second and third groups were recruited from the CPA franchise in Longueuil, Quebec (participants were not duplicated in the database sample) and from Conditionnement Physique Boucherville by soliciting volunteers directly in the class in January 2016.

\section{Questionnaires}

Participants received six questionnaires: the first addressed personal characteristics; the second was the Exercise Benefits and Barriers Scale (EBBS) ${ }^{18}$; questionnaires 3 through 5 addressed perceptions of the course and instructor; and questionnaire 6 addressed non-participation. Questionnaires were sent at 2-week intervals beginning 11 January 2016. Beginning with the second questionnaire and on all following questionnaires, we asked participants to report the number of courses in which they had participated in the previous weeks.

Participant characteristics: We collected data on age, education, family structure, ethnicity and revenue. We asked participants' weight and height, and calculated body mass index (BMI, $\mathrm{kg} / \mathrm{m}^{2}$ ). Participants reported their physical condition (very good, good, average, fair, poor), and the number of courses in which they participated at the beginning and end of the course period.

Exercise Barriers and Benefits Scale: The EBBS ${ }^{18}$ assesses perceptions of barriers and benefits associated with exercise. Participants respond whether they strongly agree, agree, disagree or strongly disagree with each of 43 statements. Total scores vary from 43 to 172 , with higher scores indicating positive perceptions of the benefits of exercise and fewer perceived barriers. Cronbach's alpha in the current study was 0.83 .

Perceptions of group exercise and instructors: Questionnaires to assess perceptions of the course and instructors were adapted to the context of the group class and French language from five existing instruments used in research on motivation (Motivation for Physical Activity Measure $^{19}$; Exercise Motivations Inventory ${ }^{20}$ ), self-regulation (Self-Regulation Questionnaire ${ }^{21}$ ), cohesion (Physical Activity Group Environment Questionnaire ${ }^{22}$ ) and support of sports coaches (Perceived Autonomy Support Scale for Exercise Settings ${ }^{2324}$ ). We selected questions representing key themes of interest and modified the wording, as necessary, to reflect the group exercise context. We created questions specific to the instructor, inspired by the themes in the above questionnaires. Our final Participant Perception Questionnaire contained 51 items addressing the following themes: individuals' personal experiences (I feel comfortable with this type of exercise); perceptions of the instructor including appearance (The instructor dresses appropriately), competence (The instructor is well prepared for each session) and support (The instructor understands my personal challenges and realities); and perceptions of the group (I like the ambiance of the group). Response options ranged from 1 (does not correspond at all) to 7 (corresponds completely). To increase participation and prevent respondent fatigue, we divided these 51 questions into 3 questionnaires with 17 questions each (see online supplementary table 1). Total scores were on a scale of 51 to 357 , with higher scores indicating more positive perceptions. Cronbach's alpha for the three questionnaires was 0.85, 0.85 and 0.93.

Non-participation: Participants chose the top five reasons that they did not participate in exercise sessions from a list of 29 options (see online supplementary table 2), with an additional option for open-ended responses.

\section{Re-enrolment}

Data on enrolment were provided by the management of each organisation from their enrolment database for Spring 2016 (beginning in April) and Autumn 2016 (beginning in September).

\section{Statistical methods}

Analyses were conducted with SPSS V.22.0. We used one-way analysis of variance and $\chi^{2}$ analyses to test differences in participant characteristics among the three groups (table 1), and among participants who re-enrolled compared with those who did not. We then tested baseline predictors of participation from weeks 2-4 and 5-10 using linear regression. Based on these results, we identified covariates to include in analyses testing predictors of re-enrolment.

We analysed characteristics of participants who re-enrolled Spring and Autumn 2016 and, because the groups were similar, we created a single re-enrolment variable representing the number of times each participant re-enrolled (zero, one or two times). We tested predictors of re-enrolment using hierarchical linear regression. In block 1 , we entered sociodemographic control variables, physical condition and BMI. In block 2, we entered EBBS scores. Age, sex and EBBS scores were retained in all models; other non-significant variables were trimmed. In block 3 , we entered 
Table 1 Sample characteristics

\begin{tabular}{|c|c|c|c|c|c|c|}
\hline & $\mathrm{n}$ & Full sample & CPA database & CPA Longueuil & $\begin{array}{l}\text { Cond. Phys. } \\
\text { Boucherville }\end{array}$ & $P$ value \\
\hline Sex, n (\%) & 462 & & & & & 0.066 \\
\hline Male & & 44 (9.5\%) & $31(8.2 \%)$ & 5 (12.8\%) & $8(18.6 \%)$ & \\
\hline Female & & $418(90.5 \%)$ & $349(91.8 \%)$ & $34(87.2 \%)$ & $35(81.4 \%)$ & \\
\hline Age, years (mean, SD) & 459 & $48.6(13.6)$ & $48.7(13.2)$ & $53.4(14.9)$ & $42.3(13.9)$ & 0.001 \\
\hline Household income, n (\%) & 434 & & & & & 0.226 \\
\hline Up to $\$ 34999$ & & $27(6.2 \%)$ & $23(6.4 \%)$ & $3(8.1 \%)$ & $1(2.9 \%)$ & \\
\hline$\$ 35000-\$ 74999$ & & $125(28.8 \%)$ & $110(30.3 \%)$ & $10(27.0 \%)$ & $5(14.3 \%)$ & \\
\hline$\$ 75000$ and greater & & $282(65.0 \%)$ & 229 (63.3\%) & $24(64.9 \%)$ & $29(82.8 \%)$ & \\
\hline Level of education, $n(\%)$ & 463 & & & & & 0.361 \\
\hline High school & & 42 (9.1\%) & 34 (9.0\%) & $3(7.5 \%)$ & $5(11.6 \%)$ & \\
\hline Some college & & $120(25.9 \%)$ & $98(25.8 \%)$ & $7(17.5 \%)$ & $15(34.9 \%)$ & \\
\hline University & & 301 (65.0\%) & $248(65.2 \%)$ & $30(75.0 \%)$ & $23(53.5 \%)$ & \\
\hline Marital status, n (\%) & 462 & & & & & 0.096 \\
\hline Single & & $36(7.8 \%)$ & 26 (6.9\%) & $2(5.0 \%)$ & $8(18.6 \%)$ & \\
\hline Married & & $384(83.1 \%)$ & $319(84.1 \%)$ & $32(80.0 \%)$ & $33(76.7 \%)$ & \\
\hline Separated/divorced & & 38 (8.2\%) & $31(8.2 \%)$ & 5 (12.5\%) & $2(4.7 \%)$ & \\
\hline Widowed & & $4(0.9 \%)$ & $3(0.8 \%)$ & $1(2.5 \%)$ & 0 & \\
\hline $\mathrm{BMI}\left(\mathrm{kg} / \mathrm{m}^{2}\right.$, mean $)$ & 461 & $24.8(4.0)$ & $24.9(4.0)$ & $24.2(3.4)$ & $24.1(4.5)$ & 0.265 \\
\hline Physical condition, n (\%) & 462 & & & & & 0.585 \\
\hline Very good & & $95(20.6 \%)$ & $81(21.4 \%)$ & $7(17.5 \%)$ & $7(16.3 \%)$ & \\
\hline Good & & $260(56.3 \%)$ & 211 (55.7\%) & $26(65.0 \%)$ & $23(53.5 \%)$ & \\
\hline Average & & $86(18.6 \%)$ & $71(18.7 \%)$ & $5(12.5 \%)$ & $10(23.3 \%)$ & \\
\hline Fair & & $12(2.6 \%)$ & $10(2.6 \%)$ & 0 & $2(4.7 \%)$ & \\
\hline Poor & & $9(1.9 \%)$ & $6(1.6 \%)$ & $2(5.0 \%)$ & $1(2.3 \%)$ & \\
\hline First time in this course? $\mathrm{n}(\%)$ & 460 & & & & & 0.305 \\
\hline Yes & & $73(15.9 \%)$ & $56(14.8 \%)$ & $7(17.5 \%)$ & $10(23.8 \%)$ & \\
\hline No & & $387(84.1 \%)$ & $322(85.2 \%)$ & $33(82.5 \%)$ & $32(76.2 \%)$ & \\
\hline First time w/this instructor? n (\%) & 463 & & & & & 0.029 \\
\hline Yes & & $154(33.3 \%)$ & $124(32.6 \%)$ & $20(50.0 \%)$ & $10(23.3 \%)$ & \\
\hline No & & $309(66.7 \%)$ & $256(67.4 \%)$ & $20(50.0 \%)$ & $33(76.7 \%)$ & \\
\hline \multicolumn{7}{|l|}{ Participation no/week (mean, SD) } \\
\hline Weeks 2-4 & 442 & $1.76(0.73)$ & $1.79(0.74)$ & $1.74(0.68)$ & $1.52(0.62)$ & 0.078 \\
\hline Weeks $5-10$ & 406 & $2.49(1.74)$ & $2.66(1.86)$ & $1.92(0.82)$ & $1.63(0.59)$ & 0.001 \\
\hline Re-enrolment, n (\%) & 463 & & & & & 0.061 \\
\hline Spring 2016 only & & $97(21.0 \%)$ & $86(22.6 \%)$ & $6(15.0 \%)$ & $5(11.6 \%)$ & \\
\hline Autumn 2016 only & & $38(8.2 \%)$ & 27 (15.0\%) & $3(7.5 \%)$ & $8(18.6 \%)$ & \\
\hline Both Spring and Autumn & & 252 (54.4\%) & 201 (52.9\%) & 27 (67.5\%) & $24(55.8 \%)$ & \\
\hline
\end{tabular}

BMI, body mass index; CPA, Cardio Plein Air.

participation from weeks 2-4. In block 4, we entered Participant Perception Questionnaire scores from categories related to the individual, followed by the instructor in block 5 and the group in block 6 . Non-significant predictors were trimmed to reach the final model (table 2). To highlight individual questions that might be particularly predictive of re-enrolment, we repeated analyses by entering individual items from each questionnaire rather than the predefined categories.

Finally, based on results of the above analyses, we tested whether perceptions of the group mediated the relationship between participation from weeks 2-4 and re-enrolment using the PROCESS macro for SPSS V.2.11(Hayes 2013). 
Table 2 Predictors of re-enrolment

\begin{tabular}{|c|c|c|c|c|}
\hline \multirow[b]{2}{*}{ Variable } & \multicolumn{2}{|c|}{ Values after entry of each variable } & \multicolumn{2}{|l|}{ Final model } \\
\hline & $\Delta \mathbf{R}^{2}$ & $P$ value & $\begin{array}{l}\text { Standardised } \\
\text { coefficient }(\boldsymbol{\beta})\end{array}$ & $P$ value \\
\hline Age & 0.094 & $<0.001$ & 0.24 & $<0.001$ \\
\hline Sex & 0.000 & 0.880 & 0.00 & 0.995 \\
\hline EBBS score & 0.000 & 0.899 & -0.08 & 0.120 \\
\hline Early participation & 0.014 & 0.015 & 0.11 & 0.029 \\
\hline Perceptions of instructor: support & 0.010 & 0.037 & 0.03 & 0.610 \\
\hline Perceptions of group & 0.011 & 0.027 & 0.15 & 0.027 \\
\hline
\end{tabular}

\section{Qualitative methods}

Six participants (four women, two men) from the Longueuil sample and five (four women, one man) from Boucherville participated in $30 \mathrm{~min}$ semidirected group interviews, as in similar studies. ${ }^{25}$ Our sample was intentional and voluntary; participants were solicited directly in class. Interviews addressed three main categories: perceptions of the instructor, the group and the exercise sessions. Interviews were recorded and transcribed. We conducted content analysis to identify common themes in each category. ${ }^{172627}$ Text was coded by the first author and two other researchers. Interjudge agreement was $79 \%$. Analyses were conducted on the original French text. Quotations illustrating themes were translated into English for publication by a professional translator.

\section{RESULTS}

\section{Descriptive statistics}

We recruited 380 participants from the CPA database, 40 from Longueuil and 43 from Boucherville. Fifty one responded to fewer than $50 \%$ of questions and were removed from analyses, leaving 463 participants. The sample was primarily composed of women $(90.5 \%)$. Most participants were white $(94.1 \%)$, French speaking $(97.0 \%)$ and originally from Canada $(95.9 \%)$. Prevalence of re-enrolment was $75.4 \%$ for the Spring period and $62.6 \%$ for Autumn. Table 1 summarises key characteristics.

Participants in focus groups were older, on average, than those who did not participate ( 58.6 vs 48.4 years, $\mathrm{P}=0.018)$. Men were over-represented in the interview sample $(n=3,30 \%)$ compared with the full sample $(n=41$, $9.1 \%$ ), although the difference was not statistically significant $(\mathrm{P}=0.060)$. Tests of means and $\chi^{2}$ analyses showed no other differences in terms of control variables such as BMI, level of education, income or ethnicity; scores on the EBBS and perception questionnaires; participation; or re-enrolment (analyses not shown).

\section{Predictors of participation}

Age $(\beta=0.20, \mathrm{P}<0.001)$ and EBBS scores $(\beta=0.10, \mathrm{P}=0.040)$ were positively associated with participation from weeks 2-4 (early participation). Physical condition, BMI and sociodemographic variables other than age did not predict participation. From weeks $5-10$, age $(\beta=-0.05$, $\mathrm{P}=0.308)$ and EBBS scores $(\beta=0.02, \mathrm{P}=0.659)$ were no longer significant predictors. Only early participation predicted later participation $(\beta=0.13, \mathrm{P}=0.015)$.

\section{Predictors of re-enrolment}

Table 2 summarises linear regression analyses testing predictors of re-enrolment. Age was positively associated with re-enrolment $(\beta=0.24, \mathrm{P}<0.001)$. Sex and EBBS scores did not predict re-enrolment. Perceptions of support received by the instructor predicted re-enrolment at entry into the model $(\mathrm{P}=0.037)$. However, this relationship was no longer significant $(\mathrm{P}=0.610)$ once perceptions of the group social climate $(\mathrm{P}=0.027)$ were added into the model. Perceptions related to the individual such as feelings of achievement, and other perceptions of the instructor such as appearance and competence, did not predict re-enrolment.

Analyses of individual questionnaire items confirmed the importance of the group social climate. Items that predicted re-enrolment included Members of our group sometimes socialise outside of the course, Our group is united in its beliefs about the benefits of the physical activities offered in this exercise course, and I like the ambience of the group.

\section{Mediation analyses}

We used mediation analyses to test links between participation from weeks 2-4, perceptions of the group and re-inscription observed in regression analyses. In addition to a direct relationship of early participation on re-enrolment ( $\beta=0.01, P=0.022)$, we noted indirect effects of early participation through perceptions of the group (95\% CI 0.0036 to 0.0471$)$. Early participation predicted perceptions of the group $(\beta=2.11, \mathrm{P}=0.003)$, which in turn predicted re-enrolment $(\beta=0.01, \mathrm{P}=0.006)$. Thus, perceptions of the group were a significant mediator of the relationship between early participation and re-enrolment (figure 1).

\section{Non-participation}

The top reasons for non-participation included interference with family responsibilities (cited by $34.1 \%$ of participants), schedule conflicts $(26.1 \%)$, health problems $(25.9 \%)$, injuries $(25.5 \%)$ and lack of time $(24.8 \%)$. 


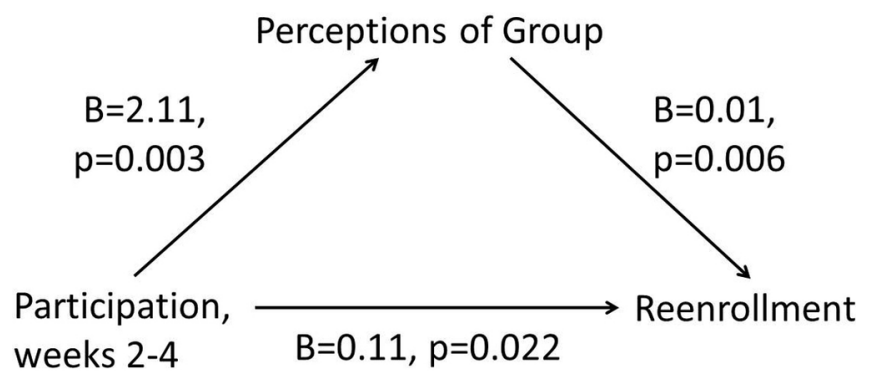

$$
\begin{gathered}
\text { Indirect (mediation) effect : } \\
95 \% \mathrm{Cl}=0.004,0.047
\end{gathered}
$$

Figure 1 Summary of mediation analyses testing relationships between early participation, group perceptions and re-enrolment.

Open-ended responses also included weather (eg, 'It's too cold in winter', $24.4 \%$ ), and vacations and travel (eg, 'Travel during spring break', 19.9\%).

\section{Qualitative results}

Figure 2 summarises four categories with 17 themes that characterise interview responses.

\section{Perceptions of the instructor}

Participants had positive perceptions of instructors in general. Underlying themes were related to instructors' abilities to explain and demonstrate the material ("She took the time to ask at the beginning, who had never done it before, and she was careful during the class, she showed the movements and paid attention to us. It's thanks to her that I'm still here today."), to correct participants when necessary ("Very attentive, she has a watchful eye-you don't notice it, but she knows when we do something wrong."; "She's not shy, and it's OK when she shows us the right way.") and to offer variety ("Every session, every year, she'll include new stuff we've never seen before."). A second theme revealed the importance of recognising individuals ("She remembers not only names, but who has a knee injury, who has a shoulder injury, very good coaching...”) and developing social connections ("When we go back to our cars, she usually walks over with everyone, she comes over to see us..."). A third theme highlighted the ability to personalise the exercises ("When some people can't do something, she always finds a different exercise, one that is demanding but also will protect someone who has knee or shoulder pain"). Finally, a fourth theme addressed the instructors' personality and attitude in the course ("She's dynamic, she's into it.").

Perceptions of the group: Participants emphasised the importance of the group social climate ("You get out of the house, see people, that helps create bonds"; "The group is really what's keeping us together, because I don't think I would have done this for 15 years alone in my basement."). They also appreciated group tasks and

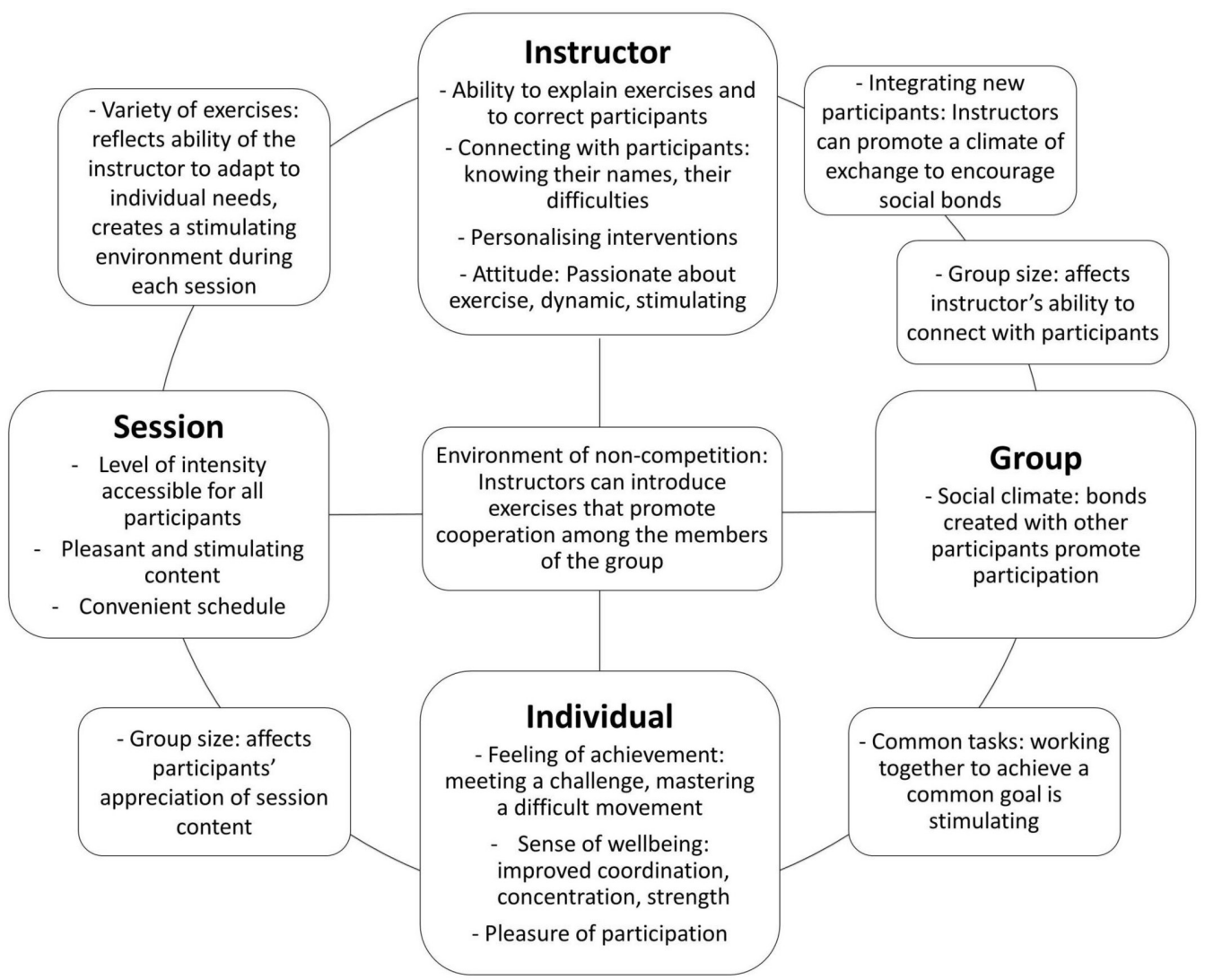

Figure 2 Key factors affecting participants' perceptions of the course and instructor. 
working towards common goals ("We all do the same thing at the same time and we all look in the same direction"; "We feel energised when we see other people doing it too."). Integration into the group is critical to avoid feelings of isolation among new participants ("Our group is strong so for someone new, that aspect can be difficult, even intimidating, very intimidating."). Finally, participants highlighted that group size affects interactions ("There might be more interactions if the group were smaller...").

Perceptions of the exercise sessions: Key factors that participants liked and disliked about the sessions mirrored discussions about the instructor, including the importance of variety in content and intensity ("She gives different levels of intensity that you can do, there's exercises that you can do more walking or instead you can jump, so... it's well adapted."). They re-emphasised the importance of group social support in completing the tasks ("We stimulate each other."). They also noted practical aspects that affected their perceptions of the session, such as group size ("If there are 30 people, it's more crowded and it gets hot a little quicker") and the time ("What I find difficult is the schedule, 8:35-9:35 p.m..."; "I've continued because the schedule is convenient for me.")

Perceptions related to individual experiences: Participation was linked to a feeling of achievement ("[It's fun when] you can finally do it, like sometimes there's a little movement and you're stuck, but in the end you get it."; "The more it goes the more we like it because we improve, and it gives us confidence"), and perceived benefits such as improved coordination, concentration and strength ("When you get out of there you feel good... it gives me energy."; "For balance... in the beginning I was all crooked and now I can do it, so that improvement is encouraging, it keeps me going."). Finally, participants enjoyed the sessions and continued because of the pleasure of participation ("I've started to have as much fun as her [the instructor]. You want to have fun with her, it's kind of like a party.")

\section{DISCUSSION}

We used mixed methods to analyse relationships among participants' perceptions of group exercise courses and instructors, and participation. Our quantitative analyses demonstrate that perceptions of barriers and benefits associated with exercise affect early participation. Major barriers such as family obligations, lack of time and injuries have been mirrored in other studies. ${ }^{28}{ }^{29}$ Openended responses highlighted others that have been less commonly discussed, including weather and vacations. Whereas participants and instructors cannot necessarily change these barriers, sensitising participants to their effects on participation might promote adherence.

Predictors of re-enrolment included age, early participation and perceptions of the group social climate. Similar research has shown that perceptions of the group social climate predict satisfaction with group exercise courses. ${ }^{11}{ }^{30}$ The importance of the social climate in our study is further emphasised in mediation analyses, which show that people who participate more in early sessions are more likely to re-enrol largely because they have more positive perceptions of the group. Measures of social cohesion have been shown to fluctuate over time in group exercise courses, and represent a target for interventions to improve adherence. ${ }^{15}$ Our qualitative results suggest that instructors play a key role in creating a positive social climate. Participants appreciated instructors who worked to integrate new participants and to promote exchange. Interventions employing instructor-led socialisation during cool-down periods can improve both short-term and long-term exercise adherence. ${ }^{14}$ In addition, instructors can create sessions that promote interaction, such as exercises to do in teams. ${ }^{31}$

Results linking group task cohesion to adherence are mixed. Past research suggests that social cohesion is a more important predictor of re-enrolment than task cohesion. ${ }^{32}$ However, task cohesion predicts adherence in some studies, ${ }^{14}$ and our qualitative results highlight the importance of perceptions of working together as a group. Interventions that focus on setting group goals to promote task cohesion can improve adherence. ${ }^{14}$ These might be incorporated into social interventions, particularly in early sessions.

Perceptions of instructors' appearance and competence were not significant predictors in any models, and instructor support did not predict re-enrolment once perceptions of the group were taken into account. Past research has similarly shown that instructor behaviour such as encouragement is not necessarily predictive of satisfaction. ${ }^{30}$ Rather, a change in encouragement predicts satisfaction: participants show higher satisfaction on days when instructors provide more encouragement than usual. ${ }^{11}$ However, our qualitative analyses highlight participants' appreciation of instructors who provided personalised support and who promoted social exchange, with themes overlapping those discussed in the group social context.

Similarly, individual characteristics such as competence did not predict re-enrolment. Past research has shown that between-person variance in perceptions of competence does not predict satisfaction but, rather, fluctuations in individual competence over time-that is, when individuals feel more competent than usual, their satisfaction is greater. ${ }^{11}$ This mirrors our qualitative results highlighting the importance of feelings of achievement. Instructors could emphasise personal improvements and offer variations in exercises that allow participants to push their abilities with each session to improve satisfaction and adhesion. ${ }^{11}$

\section{Strengths and limitations}

This study uses a mixed-methods approach, which provides rich data that allow us to contextualise perceptions through multiple avenues. We used questionnaires designed specifically to address perceptions of group 
exercise courses in a large quantitative sample. However, generalisability might be limited by the sample, representing white French-speaking women from Quebec, and the high re-enrolment rates. Furthermore, we cannot account for physical activity outside of the courses at our sample locations. Finally, whereas our questionnaires were inspired by validated instruments, our adaptations should be validated in future research, in different samples and over time.

\section{CONCLUSION}

Our results highlight the key role of the group social context in group exercise courses, as well as early participation, which predicts more positive perceptions of the group. Sensitising participants to the importance of early participation, developing strategies to promote social exchange and focusing on integrating new participants during the first few weeks might promote adherence. Given the large numbers of adults who participate in group exercise courses and their importance in helping them meet recommended levels of physical activity, ${ }^{11}{ }^{12}$ these results are important for instructors who wish to improve adherence, and in the broader context of promoting lifelong physical activity.

Acknowledgements We are grateful to Cardio Plein Air and Conditionnement Physique Boucherville for their interest in our study and their collaboration in our data collection. We greatly appreciate the help of Zachary Gaudreault in the coding of our qualitative data, and Marie-Claude Guy's careful translation of key quotations from our interview data.

Contributors MG, PC, AK and KD designed the study, including the quantitative and qualitative data collection tools. MG collected and cleaned the data. MG and $\mathrm{KD}$ conducted the statistical analyses. MG, PC, AK and KD conducted the qualitative analyses. All authors contributed to the interpretation of results, and drafting and revision of the paper.

Funding KD was supported by a salary award from Fonds de Recherche duQuébec - Santé while working on this study.

Competing interests None declared.

Ethics approval This study was approved by the human research ethics committee at the Université du Québec à Montréal. All participants provided informed consent.

Provenance and peer review Not commissioned; externally peer reviewed.

Open Access This is an Open Access article distributed in accordance with the Creative Commons Attribution Non Commercial (CC BY-NC 4.0) license, which permits others to distribute, remix, adapt, build upon this work non-commercially, and license their derivative works on different terms, provided the original work is properly cited and the use is non-commercial. See: http://creativecommons.org/ licenses/by-nc/4.0/

(C) Article author(s) (or their employer(s) unless otherwise stated in the text of the article) 2017. All rights reserved. No commercial use is permitted unless otherwise expressly granted.

\section{REFERENCES}

1. Hallal PC, Andersen LB, Bull FC, et al. Global physical activity levels: surveillance progress, pitfalls, and prospects. Lancet 2012;380:247-57.

2. Statistics Canada. Canadian Health Measures Survey: Directly measured physical activity of Canadians, 2012 and 2013. 2015. http://www.statcan.gc.ca/daily-quotidien/150218/dq150218c-eng. htm (accessed 24 Jan 2017).

3. Garriguet D, Colley RC. A comparison of self-reported leisure-time physical activity and measured moderate-to-vigorous physical activity in adolescents and adults. Health Rep 2014;25:3-11.
4. Tucker JM, Welk GJ, Beyler NK. Physical activity in U.S. adults: compliance with the Physical Activity Guidelines for Americans. Am J Prev Med 2011;40:454-61.

5. Warburton DE, Nicol CW, Bredin SS. Health benefits of physical activity: the evidence. CMAJ 2006;174:801-9.

6. Bauman AE, Reis RS, Sallis JF, et al. Correlates of physical activity: why are some people physically active and others not? Lancet 2012;380:258-71.

7. Stacey D, Hopkins M, Adamo KB, et al. Knowledge translation to fitness trainers: a systematic review. Implement Sci 2010;5:28.

8. International Health, Racquet Sportsclub Association (IHRSA). IHRSA Health Club Consumer Report: Consumer Research FAQs. Boston: IHRSA, 2010.

9. Dishman RK, Sallis JF, Orenstein DR. The determinants of physical activity and exercise. Public Health Rep 1985;100:158-71.

10. Robison JI, Rogers MA. Impact of behavior management programs on exercise adherence. Am J Health Promot 1995;9:379-82.

11. Maher JP, Gottschall JS, Conroy DE. Perceptions of the activity, the social climate, and the self during group exercise classes regulate intrinsic satisfaction. Front Psychol 2015;6:1236.

12. Melton D, Dail TK, Katula JA, et al. Women's perspectives of personal trainers. Sport J 2011;14:104.

13. McClaran SR. Effectiveness of personal training. IJOSTHE (International Journal of Sports Technology and Human Engineering)

14. Estabrooks PA, Carron AV. Group cohesion in older adult exercisers: prediction and intervention effects. J Behav Med 1999;22:575-88.

15. Dunlop WL, Falk CF, Beauchamp MR. How dynamic are exercise group dynamics? Examining changes in cohesion within classbased exercise programs. Health Psychol 2013;32:1240-3.

16. Carron AV, Brawley LR, Cohesion C. Measurement Issues. Small Group Research 2000;31:89-106.

17. Poisson Y. L'approche qualitative et l'approche quantitative dans les recherches en éducation. Rev Sci Edu 1983;9:369-78.

18. Sechrist KR, Walker SN, Pender NJ. Development and psychometric evaluation of the exercise benefits/barriers scale. Res Nurs Health 1987;10:357-65.

19. Ryan RM, Frederick C, Lepès D, et al. Int J Sport Psychol 1997;1997:335-54

20. Markland D, Hardy L. The exercise motivations inventory: Preliminary development and validity of a measure of individuals' reasons for participation in regular physical exercise. Pers Individ Dif 1993;15:289-96.

21. Ryan RM, Connell JP. Perceived locus of causality and internalization: examining reasons for acting in two domains. J Pers Soc Psychol 1989;57:749-61.

22. Estabrooks PA, Carron AV. The Physical Activity Group Environment Questionnaire: an instrument for the assessment of cohesion in exercise classes. Group Dynamics: Theory, Research, and Practice 2000;4:230-43.

23. Hagger MS, Chatzisarantis NLD, Hein V, et al. The perceived autonomy support scale for exercise settings (PASSES): Development, validity, and cross-cultural invariance in young people. Psychol Sport Exerc 2007;8:632-53.

24. Gillet N, Vallerand RJ, Paty E, et al. French validation and adaptation of the perceived autonomy support scale for exercise settings to the sport context. Int J Sport Exerc Psychol 2010;8:117-28.

25. Rose EA, Parfitt G. A quantitative analysis and qualitative explanation of the individual differences in affective responses to prescribed and self-selected exercise intensities. J Sport Exerc Psychol 2007;29:281-309.

26. Mukamurera JL, F.; Couturier Y. Des avancées en analyse qualitative: pour une transparence et une systématisation des pratiques. Recherches Qualitatives 2006;26:110-38.

27. Patton MQ. Qualitative research and evaluation methods. 3rd edn. London: Sage Publications 2001

28. Huberty JL, Ransdell LB, Sidman C, et al. Explaining long-term exercise adherence in women who complete a structured exercise program. Res Q Exerc Sport 2008;79:374-84.

29. Pridgeon L, Grogan S. Understanding exercise adherence and dropout: an interpretative phenomenological analysis of men and women's accounts of gym attendance and non-attendance. Qualitative Research in Sport, Exercise and Health 2012;4:382-99.

30. Bray SR, Millen JA, Eidsness J, et al. The effects of leadership style and exercise program choreography on enjoyment and intentions to exercise. Psychol Sport Exerc 2005;6:415-25.

31. Kleinert J, Ohlert J, Carron B, et al. Group dynamics in sports: an overview and recommendations on diagnostic and intervention. Sport Psychol 2012;26:412-34.

32. Spink KS, Carron AV. Group cohesion effects in exercise classes. Small Group Res 1994;25:26-42. 